\title{
DERECHOS HUMANOS Y RELIGIOSIDADES
}

\section{HUMAN RIGHTS AND RELIGIOSITIES}

\section{Helio Gallardo \\ Escuela de Filosofía, Universidad de Costa Rica}

\begin{abstract}
Resumen
El artículo expone una concepción sociohistórica de derechos humanos y muestra que el vínculo entre sociedad civil y religiosidades (y en especial sus formas institucionalizadas, o sea, plasmadas en iglesias, como es el caso del catolicismo) tiene un polo fuerte (la sociedad civil) y uno débil (las iglesias). En el campo de derechos humanos, las iglesias no pueden oponerse al Estado ni a la sociedad civil. Vale para todos los Estados que han firmado los protocolos y pactos de derechos humanos. De esta manera una iglesia, por ejemplo, puede rechazar la práctica homosexual en su seno, pero no puede perseguir ni acosar de forma alguna esta práctica en la existencia social. No se está ante una situación ética, sino de juricidad ciudadana. Los ciudadanos pueden darse las prácticas sexuales que deseen mientras no constituyan delito. Los grupos religiosos pueden rechazar determinadas prácticas para sus miembros, pero no pueden hacer de su rechazo una cuestión política. Un subtema del artículo es que instituciones religiosas y derechos humanos no se articulan constructivamente de modo espontáneo, sino que pueden diferir y enfrentarse.
\end{abstract}

Palabras clave: derechos humanos, religiosidades, sociedad civil, iglesias, Estado.

\begin{abstract}
The article exposes a socio-historical conception of human rights and shows that the link between civil society and religiosities (and especially their institutionalized forms, that is, embodied in churches, as is the case of Catholicism) has a strong pole (civil society) and a weak one (the churches). In the field of human rights, churches cannot oppose either the State or civil society. It is valid for all the States that have signed the Protocols and Pacts of Human Rights.

In this way a church, for example, can reject homosexual practices in its midst, but cannot persecute or harass in any way these practices in social existence. It is not before an ethical situation but of citizen juridicity. Citizens can give themselves the sexual practices they wish while they do not constitute a crime. Religious groups can reject certain practices for their members but cannot make their rejection a political issue. A sub-theme of the article is that religious institutions and human rights are not constructively articulated spontaneously but can differ and be confronted.
\end{abstract}

Keywords: Human Rights, Religiosity, Civil Society, Churches, State. 


\section{Despejar un estereotipo acerca de derechos humanos}

Uno de los estereotipos más difundidos (aunque no por ello de los más peligrosos) con respecto a derechos humanos consiste en atribuirlos a una naturaleza o esencia humana, de modo que cada individuo nacería con ellos. "Derechos Humanos" resultarían así un referente de la Humanidad. En realidad, en la expresión 'derechos humanos', el término 'derechos' remite a un factor o situación que puede ser reclamado en circuitos judiciales, nacionales o internacionales. Lo usual es que el violador de estos derechos sea un Estado, o sea, el Estado en cuyo territorio se ha cometido la violación sin que se repare el daño y se castigue a los culpables. Derechos humanos efectivos se diferencian de esta manera de expectativas y demandas por derechos (que pueden generarse en necesidades situacionales de individuos y sectores sociales) que, por no estar incorporados a la legislación o estarlo bajo la categoría de 'derechos progresivos', no pueden ser por completo reclamados jurídicamente. Por ejemplo, el Pacto Internacional de Derechos Económicos, Sociales y Culturales en su Parte 2, artículo 2.1, señala: "Cada uno de los Estados Partes en el presente Pacto se compromete a adoptar medidas, tanto por separado como mediante la asistencia y la cooperación internacionales, especialmente económicas y técnicas, hasta el máximo de los recursos de que disponga, para lograr progresivamente, por todos los medios apropiados, inclusive en particular la adopción de medidas legislativas, la plena efectividad de los derechos aquí reconocidos" (las itálicas no están en el original). Como se advierte, estos derechos, entre los cuales se encuentran, por ejemplo, la seguridad social (art. 9) y una educación orientada "hacia el pleno desarrollo de la personalidad humana y del sentido de su dignidad" (art. 13), están limitados por los recursos económicos que posea un Estado y por su progresividad (que puede referirse a su cobertura educacional limitada aunque en expansión, o a la preparación de los profesionales responsables del proceso educativo, por ejemplo), de modo que un Estado determinado podría alegar que se esfuerza por cumplir con estos derechos, pero carece de los recursos materiales y humanos para llenar las demandas. Así, no los cumple, pero tampoco los viola. Los cumplirá en algún futuro. Esta posibilidad muestra que los derechos humanos, al menos los económicos sociales y culturales, no se siguen de una 'natural dignidad humana', sino que son enteramente sociohistóricos. Un Estado los reconocerá si posee los recursos para hacerlo.

Se podría argumentar que lo anterior no vale para los Derechos Civiles y Políticos pactados, asimismo, internacionalmente en 1966 y vigentes desde la década siguiente. Entre ellos algunos pueden suspenderse justificando la 
suspensión (la libertad de tránsito, por ejemplo) y otros se consideran absolutos (a no ser torturado, por ejemplo). Pero bastaría recordar que un Estado, EUA, no reconoce ni firma los acuerdos internacionales de derechos humanos, de modo que estos no pueden aplicárseles por tribunales que no sean estadounidenses a sus ciudadanos ni a sus políticos ni militares. Escribe un autor insospechable en este campo, Michael Ignatieff: "Desde que Eleanor Roosevelt presidió el Comité que redactó la Declaración Universal, Estados Unidos ha promovido normas basadas en los derechos humanos en todo el mundo, resistiéndose al mismo tiempo, a que esas normas se apliquen a los ciudadanos y a las instituciones estadounidenses" (40). Ignatieff estima que este excepcionalismo estadounidense se deriva de considerar su ciudadanía (incluye a sus políticos) que la legitimidad de derechos humanos se basa en las respectivas soberanías populares nacionales. No tiene importancia si el argumento de Ignatieff es o no correcto. Lo que interesa es que la noción de 'soberanía popular, o sea, ciudadana nacional' es enteramente sociohistórica, no 'natural'. Y esto se da en el marco de los países considerados occidentales.

Si se remite uno a otra cultura como la hindú, el punto se torna todavía más patente. Escribe Ramchandra Pandeya:
Desde el comienzo debe señalarse que en sánscrito clásico no existe una palabra que signifique "derechos" en el sentido contemporáneo del término. En todos los contextos la idea de "exigencia justa" se expresa por medio de la palabra adhikara. Pero esta palabra difícilmente se utiliza aislada, sino más bien en el contexto, ya sea de la realización de un acto o de algún tipo de adquisición. La palabra adhikaria, que designa a una persona que tiene adhikara casi siempre sugiere que la persona ha llevado a cabo un dharma (obligación prescrita) o bien ha llegado a poseer algo, un valor o un status (...) Para el hindú todo derecho es adquirido, es decir que no es natural; en segundo lugar la adquisición de cualquier derecho es el resultado de una acción propia o del propio status (295-296).

En esta versión los derechos aparecen siempre relacionales y situacionales. Nadie nace con derecho alguno. Todos los derechos se determinan relacional y situacionalmente. Resultan enteramente sociohistóricos.

Un autor, Norberto Bobbio (1909. 2004), que casi toda su existencia sostuvo una concepción derivada del iusnaturalismo con respecto a derechos humanos, reconoció finalmente que ellos se seguían de las conflictividades objetivas y subjetivas inherentes a las sociedades modernas:

La libertad religiosa es efecto de las guerras de religión, las libertades 
civiles, de las luchas de los parlamentos contra los soberanos absolutos, la libertad política y las sociales, del nacimiento, crecimiento y madurez del movimiento de los trabajadores asalariados, de los campesinos con pocas posesiones o de los jornaleros, de los pobres que exigen a los poderes públicos no solo el reconocimiento de la libertad personal y de la libertad negativa, sino también la protección del trabajo frente al paro, y los instrumentos primarios de instrucción contra el analfabetismo, y sucesivamente la asistencia de la invalidez y la vejez, todas necesidades que los propietarios acomodados podían satisfacer por sí mismos (18).

Esta afirmación todavía podría contener una referencia a una común "dignidad humana" que subyacería a los distintos sectores e individuos que protagonizaron esas luchas, pero es también relacional y disipa otro estereotipo muy común incluso entre los activistas latinoamericanos de derechos humanos: los derechos humanos se divorcian de las violencias. Por el contrario, los grupos humanos que aspiran a que se les reconozcan ciertos derechos asumen que son socialmente violentados y que el reconocimiento jurídico de los que reclaman pueden hacer violencia a otros sectores de la población. Resulta muy sencillo ilustrar esto en las sociedades latinoamericanas actuales debido a las disputas y movilizaciones encontradas que despiertan la legalización del aborto, el matrimonio entre homosexuales masculinos y lesbianas y, desde luego, la opción homosexual. Quienes adversan los reclamos de derechos en estos campos suelen señalar como argumento que se trata de "crímenes" (e irrespeto a la voluntad divina) y de opciones que van 'contra natura'.

En todo caso, lo que interesa en relación con el estereotipo que se comenta es que los derechos humanos son todos sociohistóricos (los ya reconocidos en legislaciones y pactos internacionales y los que podrían serlo) y han sido generados por las conflictividades inherentes a las sociedades contemporáneas. Sus vínculos centrales se establecen con la integración de la existencia social y personal, pero solo por esta mediación pueden asociarse con una pacificación de la existencia social determinada por un nuevo carácter de sus relacionalidades.

\section{Un estereotipo acerca de derechos humanos ligado al campo de las religiosidades e iglesias}

El inicio del siglo XXI ha resultado especialmente preocupante para los derechos humanos. En el marco de una mundialización en la que los Estados nacionales resultan reconfigurados, aunque no desaparecen, por su inserción en constelaciones de poder internacionales y transnacionales (Organización Mundial de Comercio, Organización del 
Tratado del Atlántico Norte [OTAN] con alcance planetario, Mercado Mundial, por ejemplo), cuya acción se torna débil o disfuncional (y muchas veces irritante), el desempeño de organismos como las Naciones Unidas o la Organización de Estados Americanos (OEA) generados por la geopolítica tras la Segunda Guerra Mundial (1939-1945), ciertos derechos a los que se creía ya firmemente establecidos, han sido puestos en duda. En el siglo y en el seno de la mundialización el planeta vio surgir, desde la destrucción de las Torres Gemelas (Nueva York, WorldTrade Center, 2001), una ideología de guerra global preventiva contra el terrorismo cuyos diversos frentes ${ }^{1}$ contienen la legitimidad de la torturacontra los terroristas y sus asociados, la invasión y ocupación unilateral y no discutida de Estados y regiones con sus pobladores, el empleo de la violencia unilateral extrema contra Estados débiles o a los que se intenta debilitar, la conspiración económica, política e ideológica para 'asegurar la libertad, la seguridad y la democracia' ("primavera árabe"). La mundialización en curso complementa "éxitos" de algunos

1 La guerra global preventiva contra el terrorismo contiene, en su enunciación por Estados Unidos, cinco frentes: diplomático, militar, de espionaje, jurídico y financiero. Ninguno de estos frentes requiere concertación. El Estado que considere que tiene la fuerza para actuar, lo hace. Los terroristas son determinados por la acción de los poderosos. Los costos inmediatos son de seguridad, privacidad, libertad y vida para todas las poblaciones del planeta. Al menos Rusia y el Reino Unido se han plegado a esta doctrina planetaria. grupos con la precariedad de la existencia de millares que no encuentran empleo o seguridad en sus lugares de residencia y emigran en condiciones usualmente inestables y en las que son vejados en sus lugares de tránsito o destino. Solo en la llamada "ruta del Mediterráneo" murieron, entre enero y octubre del 2016, 3.800 emigrantes que buscaban un lugar en los países de la Unión Europea (El País, 26-10-2016). La Ruta del Mediterráneo ha sido utilizada por más de un millón de emigrantes en los últimos ochos años. Estos emigrantes no son deseados en sus lugares de origen (Argelia, Libia, Egipto, por ejemplo), se les acosa en su trayectoria por bandas de delincuentes y pobladores que lucran con sus desplazamientos y tampoco son bien recibidos (cuando les dejan permanecer) en sus lugares de destino.

En términos más amplios, la mundialización genera tanto pérdida de empleos ("población sobrante", determina Z. Bauman) como provisoriedad de ellos. Se trata de tendencias sistémicas que se fortalecerán en las próximas décadas al igual que la transformación de territorios y poblaciones desde Estados y naciones y puntos de inversión privilegiada determinados por los requerimientos del mercado mundial y provistos por las tecnologías de punta.

En este contexto de precarización de derechos humanos aparece el libro del profesor universitario inglés Stephen 
Hopgood The Endtimes of Human Rights ("Los días finales de Derechos Humanos"). Su tesis es directa:

No vivimos en la época del triunfo, sino en la de los últimos días de los derechos humanos. En nuestro mundo multipolar de poder estatal y social dispersos, los límites inherentes del modelo global de derechos humanos impulsado por organizaciones como Amnistía Internacional y Human Rights Watch se están haciendo dolorosamente aparentes. Ambas organizaciones están intentando ajustarse (...) Pero para que el concepto de derechos humanos mundiales permanezca, tiene que surgir un movimiento nuevo, más político, transnacional, flexible y ágil, que sustituya al modelo de activismo actual, de liderazgo vertical y dirigido por Occidente" (Derechos humanos: ya pasó su vida útil).

La tesis de Hopgood contiene vacíos. En realidad, la propuesta de Derechos Humanosuniversales, hecha en 1948 en las tinieblas atroces del holocausto nazi y de las masacres atómicas de la población no combatiente en Hiroshima y Nagasaki, fue una declaratoria que la constitución interna de las sociedades capitalistas de avanzada (y el consiguiente mercado mundial) no podía cumplir. Las sociedades contemporáneas inventaron derechos humanos en los siglos XVII y XVIII en el mismo complejo movimiento en el que crearon las figuras de las 'no personas' $^{\prime 2}$ e iniciaron una sacralización de los fetiches mercantiles, del dinero y del mercado. La materialización de estos fetiches torna no factibles/cumplibles los derechos humanos tanto en Occidente como en un planeta en el que las mayorías de gentes pueden ser consideradas por sectores con poder como 'malas razas', 'mujeres', 'fuerza de trabajo barata y dispensable', 'fundamentalistas' o, llanamente y sin mayor explicación, 'hostiles'. El otro 'gran vencedor de la guerra', la Unión Soviética (con su mundo acosado por la Guerra Fría y su teratologización interna), sostenía en 1948 otro concepto de derechos humanos (progresivo) y con ello la declaración, en su nacimiento, mostraba su fragilidad. Declaración importante como referente de horizonte, pero débil por razones sistémicas y geopolíticas en Occidente y también débil por razones ideológicas y también sistémicas en el campo socialista-comunista. En la situación general latinoamericana, con Estados patrimoniales, rentistas y clientelares y sociedades de status con poblaciones que

2 La no persona resulta admirablemente descrita por uno de los creadores de los derechos humanos, J. Locke: la no persona es alguien que al 'intentar' atentar contra la vida o la propiedad de otro se comporta como una bestia salvaje y debe ser liquidado (Locke capítulo III \# 16). El corolario de esta tesis es que mientras existan individuos e instituciones con capacidad para aplastar o rebajar, física o culturalmente, a otros individuos humanos, y quedar impunes, siempre existirán no personas. 
se declaran mayoritariamente católicas, la declaración del 48 y los pactos posteriores sirven para engolamientos, luchas y reclamos ocasionales y permanentes (de grupos indígenas o rurales, por ejemplo), pero carecen de reconocimiento cultural por parte de una muy desinformada población y ciudadanía.

En breve, nunca ha existido una época de triunfo para los derechos humanos planetarios. En el momento de nacer, los Derechos Humanos, con mayúscula, sus balbuceos iniciales contenían ya también sus momentos finales. Los Derechos Humanos sí han servido para salvar vidas, procurar reconocimientos y castigar responsables de violaciones, pero también han sido, y mayoritariamente, bandera cínica para atropellos y crímenes que permanecen impunes (la Guerra de Indochina y las Dictaduras de Seguridad Nacional en América Latina, por ejemplo, o la continuidad del imperio patriarcal y del hambre y la miseria, o los oídos sordos ante las movilizaciones ciudadanas por la destrucción de armamentos nucleares y el final del racismo), pero obviamente el éxito/impunidad en el atropello, relegaciones y crímenes no puede ser declarado universalmente como "triunfo".

Sin embargo, con estas y otras deficiencias, Hopgood sostiene puntos de vista interesantes y valiosos en cuanto permiten discutir. Escogemos dos. Indica Hopgood: "Serán los activistas, y no los Estados, los que cambien las cosas en el futuro. Pero, es posible que el tiempo de las organizaciones occidentales de derechos humanos también haya pasado" (Derechos humanos: ya pasó su vida útil). Las organizaciones a que se refiere Hopgood son Amnistía Internacional y Human RightsWatch. Una de las preocupaciones que llevan a Hopgood a pensar que se vive un final para los Derechos Humanos (las mayúsculas remiten a que se trata de como los entienden los Estados poderosos occidentales) es su escepticismo acerca de la capacidad que tengan Amnistía Internacional y Human RightsWatch para penetrar e influir tanto en el Sur (América Latina) como en los países no occidentales. Es desde esta prevención que postula un nuevo carácter para la promoción de derechos humanos: un liderazgo no vertical y no dirigido unilateralmente por Occidente. Lo valioso de la tesis es que se acerca a lo que ha sido la historia efectiva (no la pantomima) de los derechos humanos: han sido reclamados por sectoressociales desde los cuales emergen personalidades que representan a estos grupos sectores (Olympe de Gouges, mujeres, F. Babeuf, explotados, y M. Luther King Jr., afroamericanos, por ejemplo). Al señalar un liderazgo no unilateralmente occidental Hopgood está tocando un campo complejo y vasto que contiene tanto la diversidad de culturas y la necesidad de mutuos reconocimientos por todos los sectores, al igual que una voluntad económica y geopolítica 
de acompañamientos sin subordinaciones, como también la existencia de diversas racionalidades (y religiosidades) que pueden expresarse en una misma cultura o en culturas diferentes. Se trata de cuestiones que no han sido adecuadamente planteadas y que se han "resuelto" mediante la imposición de la cultura y de la razón occidentales como si estas carecieran de versiones distantes y no siempre conciliables en su propio seno.

Una segunda preocupación de Hopgood toca directamente a América Latina. Escribe, hablando del activismo sobre Derechos Humanos en el Sur: "Para empezar, no hay razón alguna para pensar que los Estados del sur global se comportarán de manera distinta a los Estados del norte. Los Estados son Estados. Los BRICS (Brasil, Rusia, India, China y Sudáfrica), no son un nuevo comienzo, sino aspirantes al estatus global como miembros de la hipocresía organizada de los Estados soberanos". La pregunta es:

¿Pueden las organizaciones occidentales de derechos humanos enfrentar esto si se alían de forma exitosa con grupos de la sociedad civil del sur? Hasta ahora, las ONG de occidente han fallado en la tarea de crear un vínculo con el público del sur, más allá del nivel de las élites. ¿Puede esto cambiar? Después de todo, muchas organizaciones y movimientos locales del sur mantienen creencias que no ocupan un lugar importante en el pensamiento occidental sobre derechos humanos. Estas incluyen creencias sobre la religión, la justicia, la solidaridad étnica, los derechos laborales y la importancia de la familia. Estas creencias siguen siendo aspectos vitales de sus identidades (...) ¿Qué suerte correrán los ideales de derechos humanos universales (...) con este conjunto de actores diversos y muchas veces en conflicto, cuando muchos de ellos ven a los derechos humanos como compatibles con las normas no liberales o están comprometidos con derechos sociales, económicos y culturales determinados por Human RightsWatch como una base inadecuada para una campaña eficaz? (Derechos humanos: ya pasó su vida útil, las itálicas no están en el original).

Como se advierte, existiría un Norte liberal atinado y sólido en la determinación de Derechos Humanos y un Sur (Brasil y América Latina, en lo que aquí importa) en el que solo las élites se conmueven, aunque hipócritamente, con ellos. La razón, de acuerdo con Hopgood, es que este Sur contiene no liberales religiosidades (e iglesias), creencias sobre derechos laborales, racismos y etnocentrismos y fijaciones sobre la familia. Por no liberales el 'sí mismo' cultural de estas regiones deviene incompatible con Derechos Humanos. Curiosamente, Hopgood no menciona 'nuestros' ejércitos. Pero, en efecto, nuestros Estados no son liberales (ya que se comportan como 
rentistas y clientelares), las poblaciones se adhieren en su mayoría a la Iglesia católica (un 65 o 70\%) y el catolicismo es un factor significativo, aunque difuso de la cultura de esta población y de sus identificaciones inerciales. Los latinoamericanos hemos constituido sociedades de fracturas (separatidades) sólidas y enfrentamientos brutales que terminan deslizándose con facilidad hacia aplastamientos. Y los cristianismos en uso se materializan sobre todo en expresiones pías, ingenuas y falsas o sólidamente litúrgicas y no como una forma de existencia fuera de los templos (excepto en cuanto cultura difusa que justifica cualquier tipo de acciones en interés propio) que reúna y convoque prójimos.

Lo negativo del posicionamiento de Hopgood, aun cuando no sea este su propósito, es que su determinación de las poblaciones de este Sur Latinoamericano como no liberales, facilita su inserción en el conjunto de gentes que (por no consumir con opulencia y menos producir con eficiencia) resultanprescindibles en un planeta hoy acosado en su capacidad para mantener la vidahumana en él tanto por su estilo de existencia (mundialización capitalista) como por el número de sus habitantes (su número superará los 10.000 millones en este siglo. "Sobra" mucho más de la mitad). De varias maneras esta población puede recibir la caracterización de no personas. Resultan agresores silenciosos o gritones, pero agresores al fin.

En todo caso, lo que importa en este apartado no es una prolongación para las poblaciones latinoamericanas, africanas y asiáticas, de las reflexiones de Hopgood, sino el que ellas hayan suscitado una respuesta de Larry Cox, quien ha sido tanto Secretario General Adjunto de Amnistía Internacional como codirector de Kairós (Centro para Religiones, Derechos y Justicia Social de la institución neoyorquina Union Theological Seminary). La presentación de Cox ataca directamente uno de los puntos que hemos destacado de la opinión de Hopgood:

Muchos activistas de derechos humanos son laicos y ven a la religión como un problema, en vez de como una aliada (...). Los derechos humanos y la religión se necesitan mutuamente. Aunque es posible que la universalidad de los derechos humanos requiera una presentación laica, la verdadera potencia del movimiento de los derechos humanos proviene de sus dimensiones inherentes religiosas. //Cuando los activistas de derechos humanos de nuestros días reconocen y crean vínculos con esas dimensiones, obtienen fuerza, nuevas alianzas y el aumento de legitimidad a nivel mundial que tan urgentemente necesitan (Cox, Los derechos humanos necesitan religión). 
Todos estos argumentos, centrales para la reflexión de Cox (los derechos humanos y la religión se necesitan mutuamente), descansan en la gruesa identificación entre religiones (y religiosidades) e instituciones religiosas o iglesias. Esta asociación, y con mayor razón su identificación, resulta falsa. Se puede tener fe religiosa (exaltada o tenue) y no estar adscrito a iglesia alguna o a muchas. Se puede adherir con fe religiosa a una institución religiosa determinada y carecer de la más elemental información sobre su doctrina. Y se puede tener hasta un alto cargo en una institución religiosa o iglesia y carecer de esta fe religiosa. No se discute para nada aquí si la fe religiosa surge desde el ánimo de los individuos o resulta de una gracia sobrenatural y si su materialización supone información doctrinal especializada. En un frente, resulta factible para individuos y grupos fingir fe religiosa y, en el otro, no debería resultar sorpresivo mostrar fe religiosa ardiente y no participar de iglesia alguna. $\mathrm{O}$ asistir, incluso con regularidad, a las liturgias de muchas de ellas. Existe una distancia entre religiosidad y adscripción a una iglesia. Y quienes se adscriben a alguna pueden carecer de fe religiosa o carecer de información (y del deseo de informarse) acerca de la institución en que se inscriben.

\section{Un estereotipo desde las religiosidades acerca de derechos humanos}

Superado, al menos en esta argumentación, el elemento falso de una entera identificación entre religiosidades e instituciones eclesiales conviene presentar y dialogar con otros aspectos de lo que resulta finalmente también un estereotipo, pero esta vez respecto de los vínculos entre derechos humanos y religiosidades e iglesias. Señala Cox: “... Los derechos humanos y la religión se necesitan mutuamente" (Los derechos humanos necesitan religión). En realidad, en la historia larga de la especie no lo han hecho. En primer lugar, porque no han coincidido. La especie humana, desde sus pequeños grupos iniciales y en cuanto comenzó a producir cultura, ha mostrado y comunicado sentimientos religiosos básicamente orientados a sostener sus tramas sociales (o sea, su estabilidad y supervivencia) y lo ha hecho mediante la narración de mitos (naturalistas, politeístas, monoteístas o deístas) que ligan ese entramado (sociohistórico) y su orden/violencia con espacios y seres sobrenaturales. El sentimiento religioso, hemos señalado, no requiere de iglesias, aunque bajo ciertas condiciones, puede crearlas. La primera 'iglesia' y el primer 'templo' fueron al mismo tiempo las primeras comunidades culturales. Los templos y los cultos institucionalizados vendrán mucho después. La narración literaria de Abraham puede fijarse quizás en el siglo VI a. C. 
Pero una eventual existencia de Abraham no puede datarse con los actuales instrumentos tecnológicos. Se pierde en el tiempo. Sin embargo, es también obvio que en el siglo VI a. C. no existían derechos humanos ni tampoco los había en vida de Pablo de Tarso ( 5 o 10 d. C.-58-67) y Mahoma (570-632). Estos derechos son producidos y propuestos desde imaginarios modernos y contemporáneos. Su carácter "mundial" es tan reciente como el inicio de la vigencia de los pactos sobre derechos humanos en marzo de 1976. ¡Menos de 50 años! Cuando los derechos humanos estatales y 'mundiales' aparecen, sentimientos y doctrinas religiosas tenían ya siglos. Y, de hecho, su dependencia mutua no es tal. El artículo 10 de la Declaración francesa sobre los derechos del hombre y el ciudadano (1789) señala: "Ningún hombre debe ser molestado por razón de sus opiniones, ni aún por sus ideas religiosas, siempre que al manifestarlas no se causen trastornos del orden público establecido por la ley" (las itálicas no están en el original). Está claro: todas y cada una de las opiniones o creencias religiosas (o el no tenerlas del todo) resultan legítimas. Solo se castigan como delitos si ellas son factor de violencia contra el orden público. Las personas en este orden público constituyen la llamada sociedad civil. La idea precisa es que una Iglesia (alguna, en ese momento, deseaba dominar en forma irrestricta las almas y las prácticas de sus cuerpos) no puede obligar de ninguna manera a nadie, excepto que esa persona voluntariamente acepte la obligación y mientras ella no constituya delito. La libertad de conciencia religiosa es un derecho humano y ciudadano. Conciencia religiosa y derechos humanos pueden resultar compatibles, pero solo la primera puede llegar a ser punible (un referente jurídico, no religioso) en ciertas condiciones, derechos humanos no. Cumplir con la legislación es vinculante para un ciudadano. En cambio, la salvación no resulta obligatoria para nadie. Pero tampoco a nadie se le prohíbe buscarla. Es el ethos de las sociedades modernas occidentales. Luego, una afirmación como "...derechos humanos y religión se necesitan mutuamente" es enteramente discutible y polemizable en el marco de las sociedades contemporáneas. Si existe una doctrina religiosa o iglesia que desea tener control total sobre la identidad y comportamientos de todos los ciudadanos, esta pretensión resulta ilícita. Tener creencias religiosas es legítimo, pero en el marco de una sociedad civil. Se advertirá que existe aquí una jerarquía y que en ella las religiosidades quedan subordinadas. Si quien tiene fe religiosa viola esta jerarquía, deberá responder por su transgresión en los circuitos judiciales.

En este punto específico conviene retornar a la afirmación de Cox, pero variándola desde la observación crítica anterior. '.. derechos humanos y religiosidades se necesitan mutuamente'. Pero 
'derechos humanos' resultan jurídicamente vinculantes y por ello tienen un contenido preciso. Si no fuera así, no podría reclamarse su violación en los circuitos judiciales. Ningún ciudadano puede optar por no tener derechos humanos. Aunque los rechace, los porta. La fe religiosa en cambio es una decisión privada. Por eso se la puede vivir de distintas maneras e incluso abandonarla. Mientras esa fe religiosa no implique cometer delitos ninguna autoridad pública la objetará. Si esto es así, existe una clara asimetría entre derechos humanos y fe religiosa o religiosidades, ya sea que se los considere como prácticas o como conceptos. Los primeros resultan irrenunciables en sociedades que los reconozcan. La fe religiosa es opcional u obligatoria (para quienes la estiman concedida por Dios desde el inicio de los tiempos). A esta primera asimetría se añade otra: 'derechos humanos' dicen que uno se inscribe en una determinada sociedad civil (que es un cuerpo básico y general vinculante). 'Fe religiosa' indica que uno se inscribe en una comunidad parcial y singular no vinculante, excepto por decisión propia, supeditada a la sociedad civil. De esta manera, todas las personas de una asamblea religiosa resultan ciudadanos, pero no todos los ciudadanos deben pertenecer a una u otra asamblea de fieles religiosos. El extremo socialmente débil de la relación es la comunidad de fieles religiosos. Pero en esta comunidad pueden darse creyentes blandos y duros, creyentes informados y desinformados, creyentes que hacen de su creencia una forma de vida y quienes solo la estiman liturgia en un templo, etcétera.

\section{Cuando afirma que:}

Después de todo, muchas organizaciones y movimientos locales del sur mantienen creencias que no ocupan un lugar importante en el pensamiento occidental sobre derechos humanos. Estas incluyen creencias sobre la religión, la justicia, la solidaridad étnica, los derechos laborales y la importancia de la familia. Estas creencias siguen siendo aspectos vitales de sus identidades, incluso mientras estos grupos sureños están siendo perseguidos por sus propias élites y Estados (Derechos humanos: ya pasó su vida útil, las itálicas no están en el texto).

Hopgood está pensando (en lo que respecta a América Latina) en específico en sociedades de estatus y no de rendimientos y en sociedades mayoritariamente católicas donde por definición el individuo no resulta sujeto (principio de agencia liberal) porque quien realiza su subjetividad (adherirse a Cristo Jesús) es el Espiritu Santo. Adherirse a derechos humanos en la institución católica supondría su efectiva revolución interna.

En este sentido, la argumentación alternativa de Cox resulta muy deficitaria por imprecisa. Su fórmula 
"derechos humanos y religiosidades se necesitan mutuamente" pasa por alto que identidades e identificaciones religiosas pueden predicarse dentro de un abanico muy amplio que va desde quien no tiene fe religiosa y la aparenta por razones de estatus, credibilidad e inserción, hasta quien se experimenta con esa fe e intenta hacerla presente en todos los momentos de su existencia. Los primeros no se interesan en derechos humanos excepto que les sean violados a ellos o a sus cercanos. Los segundos, en específico los católicos, se interesan en ellos, pero regularmente desde un posicionamiento negativo: no los admiten si le parecen no deseados por su iglesia (es decir, por su Dios trinitario institucionalizado). Estiman que su no admisión y sólido rechazo los acerca a la salvación. Su negatividad con respecto a derechos humanos va desde la sexualidad (un homosexual es admisible solo si no practica su "depravación grave") (Catecismo, \# 2357 y siguientes), por ejemplo, hasta la liquidación de "comunistas" contra los cuales resulta legítima la violencia (Populorum progressio, \# 30, 31). Dejamos de lado la hostilidad de la jerarquía católica hacia judíos, musulmanes y mujeres. Luego, un primer aspecto es que los sentimientos propios de una fe religiosa no son vividos por todos los fieles de una manera ya no idéntica, sino solo parecida. Y que la vivencia de una religiosidad puede contener, para algunos fieles religiosos, enconos en relación con derechos humanos que una sociedad civil compleja por diversa reclama.

En este punto Cox argumenta que algunos creyentes religiosos han tenido, "una participación extremada en los movimientos en favor de los derechos y la justicia social. Lo hacen porque con frecuencia su fe es lo que les da la inspiración moral, la legitimidad popular y la fortaleza interna para soportar grandes sufrimientos. Consecuentemente, la acción con base en la fe ha sido, y sigue siendo, una de las principales fuerzas que socavan los sistemas políticos represivos en todo el mundo" (Los derechos humanos necesitan religión). Por desgracia en el párrafo anterior no menciona la participación de los pueblos cristianos o católicos, sino a personalidades: "Óscar Romero de El Salvador, Mahatma Gandhi de la India, Shirin Ebadi de Irán, Martin Luther King de los Estados Unidos (EE. UU.) y Aung San SuuKyi de Birmania/ Myanmar". Esta mención de personalidades resulta por completo unilateral. Olvida, por ejemplo, y desde la realidad latinoamericana, que Óscar Arnulfo Romero fue aislado por la jerarquía de su iglesia (salvadoreña y vaticana), contra el sentir mayoritario de su pueblo, incluso después de su martirio, y que, así como se le menciona positiva y justificadamente a él, criminales como los generales Jorge Rafael Videla (Argentina) y Augusto Pinochet (Chile), ambos católicos, nunca fueron aislados, 
denunciados ni repudiados por estas mismas jerarquías locales y vaticanas. Y para no dejar en paz a los cristianos protestantes, así como se indica a Gandhi (para nada cristiano), uno de los mayores genocidas de Guatemala (se trata de un escalafón muy competitivo), Efraín Ríos Montt, tras dejar el catolicismo se transformó en ministro de la Iglesia Pentecostal de la Palabra.

Para no quedarnos en localismos, recordemos con tristeza que en el feroz genocidio de Ruanda (1994, 800.000 tutsis asesinados, casi todas las mujeres tutsis que sobrevivieron el genocidio fueron violadas y la mayoría de los 5.000 niños nacidos de esas violaciones resultaron liquidados) intervinieron siniestramente religiosos católicos, incluido el obispo de Gikongoro, Agustín Misago. Sobre la participación de creyentes católicos en el genocidio reproduzco un párrafo de un diario mexicano:

Entre los procesados por su participación genocida se encuentran dos monjas benedictinas: Consolata Mu-kangango (sor Gertrudis) y JulienneMukabutera (sor María Kizito), acusadas de haber contribuido en la ejecución de 7 mil tutsis que buscaban refugio en el convento de Sovu. La participación de estas "religiosas" consistió en llamar "a las milicias para que echaran del lugar a los desesperados tutsis del perímetro del convento. Les dieron gasolina a los milicianos para que quemaran a unos 500 tutsis que se habían refugiado en el estacionamiento del convento (La Jornada, 9 de junio del 2001).

No conviene olvidar que el Vaticano (Juan Pablo II) defendió y apoyó a estos genocidas. Por supuesto, no todos y cada uno de los cristianos y católicos es un criminal abyecto o un genocida. Lo que aquí se muestra es que una declarada religiosidad no inmuniza contra la crueldad ni bloquea los odios o lleva a renunciar a la cobardía abyecta. Luego, existen cristianos y católicos en lo personal generosos y bellos (y en parte deben estos caracteres a su fe religiosa), existe un buen número que vive su religiosidad como si ella lo apartara de los demás y además existe otro grupo que no experimenta incompatible ser cristiano o católico y despreciar, acosar y matar (cultural o físicamente a otros). A todos, "su fe es lo que les da la inspiración moral", según nos refiere Cox. La afirmación resulta, como se advierte, por completo vacía. Entre los quizás 10.000 soldados estadounidenses que ocupan hoy Afganistán (ocupación que empezó en el 2001) liquidando "terroristas" y creando condiciones para violar mujeres afganas sin duda existen muchos que poseen creencias cristianas. Se puede conceder que la disciplina militar los hace relegar sus sentimientos religiosos. Las cifras de muertos y lisiados afganos en 
el conflicto no pueden establecerse porque las autoridades políticas (entre las cuales ha de haber 'cristianos') y sus medios las ocultan. En abril del 2017 el presidente Trump se mostró orgulloso por haber ordenado el lanzamiento de la bomba no nuclear más grande del mundo contra el territorio y población afganos. Trump es cristiano presbiteriano. Estima que la suya es "... una maravillosa religión".

Incluso grupos budistas, independientemente de si el budismo constituye o no una religiosidad, no admiten ser agrupados mediante una denominación abstracta por general: budistas. Existen budistas interesados en lograr una purificación que los separe del sufrimiento y de la reencarnación y por ello tratan de evitar todo mal sentimiento o acción que hiera a otros y existen también budistas (Sri Lanka) que persiguen y odian a musulmanes y tamiles en nombre de una pureza étnica-cultural originaria. Tampoco gozan de la simpatía de estos budistas los cristianos occidentales (responsables de haber ingresado "forasteros" a Sri Lanka) y los politeístas (los hinduistas tamiles pueden ser budistas o politeístas, entre su alta variedad de opciones).

Desde su inconveniente generalización acerca de los creyentes religiosos, Cox estima que "Las religiones y los derechos suelen converger porque ambos creen en eso que la Declaración
Universal de Derechos Humanos llama " $<$ la dignidad inherente $>$ " de "todos los miembros de la familia humana'. Como la Declaración, la mayoría de las religiones predica el amor por todos los seres humanos y la necesidad de actuar cuando se está violando la dignidad humana". Añade Cox: "Los derechos humanos y las religiones también coinciden en afirmar que esta dignidad, y los derechos que se requieren para protegerla, no es una invención de los seres humanos o los gobiernos, sino que está presente en todos y cada uno de nosotros desde el momento en que nacemos" (Los derechos humanos necesitan religión). Pero también admite que:

Algunas de las expresiones más
espectaculares del fervor religioso
provienen de grupos que promue-
ven la violencia, la intolerancia,
la misoginia y la homofobia. En los
EE. UU., por ejemplo, el activismo
religioso se asocia frecuentemente
con ataques a los derechos de las
mujeres y la población LGBTQ,
la investigación científica y las crí-
ticas al capitalismo no regulado.
Consecuentemente, los medios y
muchos académicos suelen ignorar
las expresiones progresistas de las
religiones y ven la fe como una ex-
presión de superstición, fanatismo
o conservadurismo (Los derechos
humanos necesitan religión).

Ambas consideraciones de Cox resultan al menos imprudentes al ignorar los hechos. El punto lo conduce a 
conceptos mal formados. Una eventual 'dignidad humana' no consiste en un carácter innato de los individuos que pueda predicarse con independencia de las relaciones sociales entre ellos. No existía para sus asaltantes dignidad alguna en el judío herido en la parábola evangélica del samaritano (Lucas, 10). El desprecio que, por razones religiosas, los judíos expresaban por los samaritanos tampoco les concedía a estos últimos dignidad humana de ningún tipo ni los samaritanos exigían que los judíos les reconocieran ese estatus. Tampoco vieron (ni experimentaron) dignidad humana alguna en el herido, el sacerdote y el levita (ambos funcionarios del templo judío) que pasaron por su lado sin ayudarlo. La dignidad de los seres humanos solo aparece cuando el samaritano (despreciado racial, religiosa y culturalmente por los judíos, es decir sin ninguna dignidad humana) y el judío herido (un despreciador étnico y religioso) se reconocen el uno al otro como humanos y el primero socorre al segundo y el herido acepta la ayuda que proviene de alguien que hasta ese momento valía para él 'menos que un perro'. También hubiese surgido esta dignidad si el sacerdote y el levita hubieran atendido al herido. Quienes le robaron e hirieron no repararon en esa dignidad sino en su indefensión y sus bienes. La dignidad humana se genera mediante relacionamientos. No se puede predicar sin ellos (excepto para juegos intelectuales o discursos ideológicos) porque no existe fuera de ellos. Eso es lo que dice la parábola. Y así lo presenta Jesús de Nazaret. La versión de Cox proviene de una ideología liberal (con antecedentes medievales) o religiosa para las cuales los seres humanos nacen individuos (dignos) y luego, por su deseo, establecen relaciones (Contrato Social). Se trata de una superchería. Los individuos humanos y sus atributos nacen de relaciones sociales, el vientre de la madre humana es social y el niño nace en una trama de relaciones sociales que lo antecede. $Y$ es en tramas sociales que ese ser humano va a individualizarse.

Tampoco las religiosidades humanas expresan solo superstición, fanatismo, conservadurismo y criminalidad. Sin duda, y especialmente las iglesias institucionalizadas, pueden ejecutar estas prácticas. Pero el sentimiento religioso también resulta significativo para la integración personal de algunas o muchas personas y, con ello, estas personas pueden manifestar una expresión cordial (en los sentidos de amable y generosa) hacia los otros. No resulta adecuado negar esto. Tampoco conviene sugerir (o proclamar) que se requiera en algunos lugares del planeta una inclinación religiosa para que la cordialidad hacia otros exista. Muhammad Ali (1942-2016), el boxeador, no aceptó participar en la guerra de Vietnam porque 'esas gentes no le habían causado daño alguno ni a él 
ni a los afroamericanos estadounidenses'. Sus conciudadanos blancos sí lo habían hecho y lo siguen haciendo. Ali, como se advierte, entendía que la dignidad humana tanto de individuos afroamericanos como de asiáticos y blancos pasa por sus relacionamientos, entre ellos, el que supone su ciudadanía común, no por caracteres innatos.

Podemos finalizar aquí este examen del estereotipo que liga necesariamente religiosidad con derechos humanos. No existe tal vínculo forzoso. Menos si la religiosidad se materializa en iglesias. Tampoco se tienen derechos humanos porque se pertenezca a una determinada civilización o grupo social. Objetiva y subjetivamente los derechos humanos dependen del nivel de compromiso ciudadano humano medido por su relación con los logros o impedimentos de humanidad factibles para los ciudadanos más vulnerables en las sociedades que comparten, o más allá de ellas. En este compromiso pueden o no jugar un papel importante los sentimientos religiosos. Por ejemplo, cuánto conmueve ciudadana y socialmente a un guatemalteco la siguiente información: 'Según estadísticas del Ministerio de Educación la tasa de analfabetismo nacional es $24.8 \%$ y la de las mujeres indígenas del $73.4 \%$. En cuanto a la brecha étnica, en todos los niveles educativos desde la primaria hasta el diversificado, existe una cobertura menor conforme hay más población indígena (...) el analfabetismo indígena es de $42.5 \%$ y el analfabetismo en la mujer indígena adulta llega a un $73.4 \%$, con un promedio de escolaridad del 1.8 años, comparado a los 4.3 años que es el promedio de escolaridad nacional' ${ }^{\prime 3}$. En esta situación guatemalteca la vulnerabilidad más alta se sigue de un dominio político-cultural del campo sobre las áreas rurales, de la blancura y el mestizaje sobre lo indígena, de la pareja mutuamente excluyente entre opulencia (relativa) y miseria-pobreza, y de la dominación patriarcal de machos adultos sobre mujeres, niños $\mathrm{y}$ ancianos vigente tanto en la sociedad guatemalteca en su conjunto como en el seno de las familias indígenas. Sin embargo, aquí el punto, por ejemplo, se centra en cuán conmovido se experimenta un ciudadano guatemalteco blanco o mestizo urbano, creyente religioso o no, por esta conjunción de violaciones sistemáticas de derechos humanos a las niñas (y ancianas) rurales indígenas de su país y cuánto se comprometerá (con acciones específicas) para su superación, lo que implica tanto iniciativasestatales como transformaciones culturales, o sea de toda o la mayoría de la sociedad guatemalteca.

Un segundo aspecto es qué papel jugará en su compromiso o descompromiso

3 Referimos desde http://www.segeplan.gob.gt/ downloads/clearinghouse/politicas_publicas/ Grupos\%20Vulnerables/Pol\%C3\%ADtica\%20 $\mathrm{Ni} \%$ C3\%B1ez\%20y\%20Adolescencia.pdf 
su adhesión religiosa (y con ella su identidad radical) o su adscripción a alguna iglesia presente en Guatemala. Mal que bien, Guatemala se confiesa católica y protestante, es decir, cristiana. Pero las cifras de discriminación y postergación indígena muestran que se trata de un cristianismo con escasa o nula irradiación social. Lo que significa que una mayoría de guatemaltecos no se comportan como lo que proclaman ser. El ejemplo pudo de manera semejante darse con la indiferencia casi generalizada de los costarricenses por la violación de derechos humanos en los recintos carcelarios del país. Si estuviesen animados por una fe evangélica (un 71\% se declara católico y un $21 \%$ protestante evangélico) radical (o sea, sólidamente identitaria) no les resultaría indiferente esta situación.

\section{La cuestión de la identidad radical}

En el apartado anterior y discutiendo la observación de Larry Cox acerca de una eventual coincidencia de criterios entre creyentes religiosos y activistas de derechos humanos, se ha hablado de los primeros relacionándolos con una identidad radical. Se trata de una apreciación conceptual aplicable en especial a religiosidades teístas como los cristianismos. Lo que está en juego en estas religiosidades (y por ello en las iglesias que los albergan) es la salvación de los individuos. Se trata de una salvación trascendental usualmente referida como una existencia eterna en el Espíritu, que puede o no ser ligada por una resurrección del cuerpo ahora trascendental porque vive la experiencia de unirse al cuerpo místico de Cristo y con ello acceder a la visión de Dios. El Catecismo católico describe la situación así: "Los que mueren en la gracia y la amistad de Dios y están perfectamente purificados, viven para siempre con Cristo. Son para siempre semejantes a Dios porque lo ven "tal cual es”, cara a cara” (\#1023). La referencia es del evangelista Juan: “... y aún no se ha manifestado lo que hemos de ser; pero sabemos que cuando él apareciere, seremos semejantes a él, porque le veremos como él es (...) Y el que guarda sus mandamientos, está en él, y él en él" (1 Juan, 3). Y añade el parágrafo 1024 del Catecismo: "Esta vida perfecta con la Santísima Trinidad, esta comunión de vida y de amor con ella (...) se llama "el cielo". El cielo es el fin último y la realización de las aspiraciones más profundas del hombre, el estado supremo y definitivo de dicha". Una 'realización de las aspiraciones más profundas del hombre, el estado supremo y definitivo de dicha' no puede ser entendido sino la consumación de una identidad radical. 'Radical" en su sentido de fundamento/raíz, aquello que concede su ser efectivo al ente.

Vista así, la salvación para el cristiano católico (y en general para todos los cristianismos) no puede ser asumida superficial o epidérmicamente. $\mathrm{O}$ algo 
que se desea mientras no se lo olvida. El 'cielo' se presenta como una existencia eterna en el seno de Dios, existencia donde todo se comprende y se disfruta.

Para el cristianismo de inspiración luterana el cielo es también la meta, aunque a ella se llega por la sola fe (Sola Fide): "Los sentimientos vienen y van. Los sentimientos son engañosos; mi seguridad es la Palabra de Dios. Nada más vale la pena creer. Aunque todo mi corazón se sienta condenado queriendo alguna muestra dulce, existe algo más grande que mi corazón Cuya Palabra no puede ser quebrantada. Confiaré en la Inmutable Palabra de Dios hasta que el alma y cuerpo sean separados porque, aunque todas las cosas pasen, Su Palabra permanecerá por siempre"4. Por la acción de Jesucristo en el Cielo el alma volverá a unirse al cuerpo (separados por la muerte individual) y se tendrá una trascendente existencia eterna. La diferencia con el catolicismo no está así tanto en el carácter de la salvación (Cielo) como en los medios para obtenerla: la fe en la palabra de Dios.

Tanto en el luteranismo como en el catolicismo encontramos que la fe religiosa en la salvación constituye un referente radical para esa fe. En este sentido es que hablamos de una radicalidad

4 Tomado de https://www.thegospelcoalition. org/coalicion/article/martin-lutero-y-la-seguridad-de-la-salvacion de la identidad religiosa. No constituye apariencia. Es fundamento y horizonte.

Por supuesto, resulta factible tener una percepción light de las religiosidades. Para ello basta con relegar/olvidar su referente trascendental y observar sus apariencias (derivadas de una mirada puntual sobre los comportamientos/ actitudes habituales entre los fieles). En Costa Rica, escribe, por ejemplo, Víctor Manuel Mora Mesén, un religioso, que las religiosidades en boga en el país pueden determinarse como doctrinales, rituales, emotivas, simbólicas, mediáticas y virtuales y sus combinaciones o mezclas. Elijamos al azar tres de las religiosidades que menciona para reparar en lo que tienen de común: la religiosidad emotiva "... pretende que la experiencia religiosa impacte siempre los afectos de las personas. No importa que se trate de un acto de culto o de una conferencia, de una devoción, de un rito o de una conversación con otra persona: el objetivo es alcanzar un cierto estado emocional"s. Por supuesto, "personas" es una abstracción, entre otras, que utiliza el articulista. En una liturgia pueden coincidir adolescentes que vienen saliendo de una fiesta de la que han salido novios, madres que han perdido

5 Todas las referencias han sido tomadas de "La variopinta religiosidad contemporánea”, $\mathrm{La} \mathrm{Na}$ ción (periódico), 29/10/2017. Existe versión en Internet, fechada el día anterior, en http://www. nacion.com/opinion/foros/variopinta-religiosidad-contemporanea_0_1667233274.html 
recientemente un hijo y padres que no saben cómo pagar la próxima cuota del alquiler. Todos ellos quizás desean que esa liturgia les ayude a alcanzar o a sostener "cierto estado emocional". Son seres humanos. En la religiosidad mediática se transmitirían“... contenidos religiosos a través de las redes sociales. Se diferencia de las otras religiosidades en que se vive solo en la interconexión mediática: no necesita de instituciones o de estructuras de culto, basta con la transmisión de experiencias, doctrinas, imágenes o prácticas rituales que no exijan una sumisión obligatoria a una autoridad determinada. Ellas se entienden a sí mismas como soluciones eficaces al anhelo espiritual, así pueden ser vividas individualmente y de manera anárquica”. Aquí el analista de 'religiosidades' olvida que "anárquico" en español remite a ausencia de poder público (las iglesias pueden realizar actos públicos, pero carecen de poder público ciudadano) o a 'desconcierto' e 'incoherencia'. Al parecer echa de menos en esta religiosidad una autoridad sagrada e incontestable. La del padre o el cura, por ejemplo. Cuesta imaginar que las interconexiones mediáticas no estén mediadas por instituciones (ellas mismas son una), excepto que se considere 'institución' solo a las pétreas, como alguna iglesia. 'Individual', por supuesto, no es igual a anárquico. Materializarse como 'individuo singular' es propio de la especie humana (y no entra en conflicto con su carácter social ni eventualmente comunitario). Una tercera 'religiosidad' mencionada por el autor es la ritual. Consistiría en privilegiar “... la celebración del culto y su parafernalia. Para los que entienden de esta manera la vivencia religiosa, lo importante es cumplir con aquellas prácticas que garantizan un acercamiento con lo sagrado". 'Parafernalia' es un término pintoresco, por sus alcances inerciales (habitualidad) para asociarlo con culto religioso, y decididamente inconveniente si se trata de lo 'sagrado', según escribe el autor. Comportarse inercial con lo sagrado puede conducir al abismo, vía la idolatría. En todo caso, solo en esta religiosidad, aunque flanqueada por la parafernalia, se menciona lo sagrado. Ahora, toda religiosidad tiene que ver con lo trascendental/sagrado. Si no se establece esta relación, no se está hablando de religiosidad, sino de moda, entretenimiento, hábitos, inclinaciones, supersticiones, etcétera. En este sentido, reiteramos en su religiosidad se juega el creyente religioso su identidad más profunda y también su salvación. Es obvio que estamos tomando en cuenta centralmente los cristianismos imperantes en América Latina y otras partes del mundo.

Ahora, al menos una de estas religiosidades radicales entra en abierto conflicto con derechos humanos. Es la religiosidad católica. Un par de razones bastarán para comprenderlo. En la 
tradición judeocristiana un Dios todopoderoso crea todo lo que existe (para ello combate con aguas agitadas, tinieblas, desorden y abismos) hoy como cosmos. Dentro de esta creación, modela a la mujer y al varón: "Y dijo Dios: Hagamos al hombre a nuestra imagen, conforme a nuestra semejanza; y tenga dominio sobre los peces del mar, y sobre las aves de los cielos, y sobre las bestias, y sobre toda la tierra y sobre todo animal que se arrastra sobre la tierra. Y creó Dios al hombre a su imagen, a imagen de Dios lo creó; varón y hembra los creó. Y los bendijo Dios y les dijo Dios: Fructificad y multiplicaos; y henchid la tierra y sojuzgadla; y tened dominio sobre los peces del mar, y sobre las aves de los cielos y sobre todas las bestias que se mueven sobre la tierra" (Génesis, 26-28). Dios crea seres humanos a su imagen y semejanza, pero no iguales a Él. Esto queda claro porque les concede dominio sobre tierras y animales y, además, porque les ordena qué hacer. Estos seres humanos resultan sus creaturas (especiales, sin duda) y en relación con Él son siempre-criaturas (menores). En este sentido no son Dios porque Éste no es creado sino Creador. Es Sujeto. En cambio, los seres humanos, en la lectura más optimista, se comportan como sujetos. Un Sujeto Absoluto no admite dependencias. Los sujetos relativos sí. Se puede imaginar a los seres humanos 'libres', o con libertad, pero no son Absolutos, sino en situaciones. Pueden optar libremente, pero en condiciones que ellos no determinan por completo. Y en su relación con Dios no pueden cambiar esto.

A estos factores judeocristianos, que pueden entenderse como "Dios hace la historia aunque los seres humanos protagonicen sus designios", el catolicismo añade un criterio doctrinal también específico. Si bien Dios se hace carne en su Hijo, Cristo-Jesús, lo que podría interpretarse como que los seres humanos devienen parcialmente divinos, aunque mueran (su ciclo sería gestación, muerte, resurrección) se añade que la Iglesia católica (su institucionalidad) expresa materialmente la Revelación de Dios y con ello se torna universalmente vinculante. Sus sacramentos, en los que se hace presente el Espíritu Santo, introducen a este Espíritu en el individuo humano consagrado o en el fiel laico y lo llevan a vivir la fe en Jesús o en Cristo. El vínculo entre Espíritu Santo y Cristo Jesús en la existencia identitaria del fiel creyente y el carácter revelado de la Iglesia que administra los sacramentos (el carácter sagrado de la existencia sociohistórica) confirman la propuesta del ser humano como una creatura siempre-menor a su Creador y Señor de la Historia. Es libre, pero por la acción del pecado que expresa y lleva a la separación de Dios y de los otros seres humanos y conduce al individuo a su condena eterna. En relación con las instituciones queridas/creadas por Dios, la 
Iglesia con sus sacramentos y la familia (o la propiedad privada de medios de producción), por ejemplo, el ser humano no es libre. Esto es lo que en la liturgia se condensa en las expresiones: "Palabra de Dios", "Así sea" o el más tradicional "Amén". Toma, asimismo, cuerpo en el culto mariano ("He aquí tu sierva") y se extiende en la religiosidad popular de inspiración católica en la forma de 'fiestas patronales' (los santos son referencias de culto y hacen milagros o interceden para que ellos se cumplan) o en las sentencias con que se aceptan/asumen los dolores y tragedias de la existencia cotidiana, en especial entre los sectores más humildes: "Dios lo ha querido asî". "Es la voluntad del Señor". "Dios sabe por qué hace las cosas". Incluso el nombre de un proyecto o proceso católico costarricense reproduce este imaginario: "Obras del Espíritu Santo" supone el aposentamiento de este Espíritu en los cuerpos y almas de quienes participan o colaboran generosamente en esta empresa. Las personas que la llevan a cabo son y no son ellas en cuanto están ahí con sus donaciones y trabajos, pero las anima o nutre el Espíritu Santo.

Nada hay de perverso en la anterior ideología, pero choca de frente con la sensibilidad político-cultural de derechos humanos. Estos descansan, aunque selectivamente en el criterio de agencia humana, de inspiración liberal. El principio de agencia humana resulta compatible con fe y creencias religiosas, pero sobre todo enuncia que el ser humano, por racional y emprendedor (sujeto), es libre y capaz de crear opciones y de elegir entre ellas. 'Libertad' no quiere decir aquí reconocer la voluntad de Dios y cumplirla, sino crear opciones y tener la capacidad para discernir entre ellas y elegir. Como se las elige individual o colectivamente, se es responsable por ellas. Es en este sentido que el ciudadano tiene derechos y deberes. Ambos lo relacionan con el Estado. Las transgresiones a ese esquema no constituyen pecado sino delitos (contra las personas de la sociedad civil y el Estado). Desde un punto de vista conceptual, este criterio (que sostiene derechos humanos desde los siglos XVI y XVII) con respecto a la libertad humana no resulta incompatible con la religiosidad católica siempre y cuando esta última se mantenga como opción privada que coopera con la sociedad civil y la organización pública de la sociedad (Estado). Los problemas surgen, y los latinoamericanos lo tienen claro, para bien o para mal, cuando la Iglesia revelada "invade" el ámbito de la sociedad civil (e inevitablemente del Estado) en cuestiones que lesionan el principio liberal de agencia humana: aborto, familia lesbiana o gay, opción lesbiana o gay, fecundación in vitro, sexualidad genital sin matrimonio, técnicas anticonceptivas 'no naturales' (¿?), la proliferación de sectas, etcétera, o el carácter no confesional del 
Estado (legislar en forma positiva [o sea, reconocer jurídicamente] sobre los temas anteriores, por ejemplo). El principio liberal de agencia humana no es sagrado, sino civilmente debido. Implica que puede cambiar de acuerdo con circunstancias. En la perspectiva católica más tradicional, que domina en la institución y el personal ordenado y en menos medida entre la feligresía, distintos alcances del principio de agencia pueden ofenden la voluntad de Dios y contienen un socavamiento de los fundamentos de la sociedad y la civilización. Lo sagrado, por trascendental, suele resultar insensible a las circunstancias. Cualquiera que sea la circunstancia, el comportamiento homosexual y el aborto ofenden la voluntad de Dios y han de ser rechazados.

Para los protestantismos y sus iglesias y espiritualidades (entre un $17 \mathrm{y}$ 20 por ciento de la población costarricense), no debería existir en los temas anteriores (homosexualidad, aborto) ni en relación con el principio liberal de agencia humana mayor problema. Aunque las expresiones del protestantismo son variadas, su rechazo a sacralizar toda institución humana (que les potencia para fundar una diversidad de iglesias y para potenciar al individuo o colectivo emprendedor), el énfasis en la salvación por el constante vigor de la fe (gracia de Dios) y el estudio e interpretación bíblica (que ha potenciado una teología vigorosa y disputante), su sacerdocio universal y, en la situación latinoamericana, su penetración en los sectores bajos y medios de la ciudadanía (sin despreciar a los altos) le concede una mayor capacidad para dialogar con la sociedad moderna (racionalismo, hedonismo, polifonía) y contemporánea. Por lo demás, nació como respuesta de fe religiosa a esta sociedad. Si alguna de sus iglesias choca con determinadas exigencias de derechos humanos, los fieles de ella que las apoyen pueden crear otra asamblea sin lesionar su fe religiosa o espiritualidad. Martin Luther King Jr. fue bautista, partidario de la acción directa y de la desobediencia civil para conseguir derechos ciudadanos, pero también crítico negativo del Black Power y de la insurrección revolucionaria (Che Guevara). Valoraba que ese tipo de violencia resultaba ineficaz porque no alcanzaba sus metas. Algo semejante estimó Hélder Cámara, el obispo brasileño. Pero Cámara, sin que esto implique reproche alguno, nunca organizó una marcha semejante a la que, con otros dirigentes, impulsó Martin Luther King Jr. (Marcha sobre Washington por el trabajo y la libertad, 1963). Algunos aspectos del pensamiento de Cámara y Luther King Jr. tienden a coincidir. La diferencia la marca su trabajo político. Escribió el último:

La última debilidad de la violencia es que es una espiral descendente, que engendra lo mismo que busca destruir. En lugar de debilitar el 
mal, lo multiplica. Utilizando la violencia, podéis matar al mentiroso, pero no podréis matar la mentira, ni restablecer la verdad. Utilizando la violencia, podréis asesinar al rencoroso, pero no podréis matar el odio. De hecho, la violencia hace simplemente crecer el odio. Y esto continúa. Devolver el odio por el odio multiplicado al odio, añadiendo una oscuridad todavía más profunda que una noche sin estrellas. La oscuridad no puede esconder la oscuridad: sola la luz puede hacer esto. El odio no puede esconder el odio: solo el amor puede hacer esto (Where Do We Go from Here: Chaos or Community?).

Sin embargo, King fue revolucionario en un marco de lucha por derechos civiles y humanos. No triunfó, porque esta victoria supone la conversión de los racistas y despreciadores de las diferencias, pero su combate continúa. Cámara optó por un diálogo y conciliación con los poderosos de este mundo para que consintieran en erradicar la producción de hambrientos y vulnerables extremos en América Latina. Obviamente no logró ese consentimiento. En América Latina no resulta incompatible ser cristiano e inmisericorde.

América Latina nunca se ha mostrado particularmente proclive hacia los deísmos, pero en ellos los derechos humanos encuentran una excelente articulación con el carácter que asignan a la religiosidad. Como ella no puede contener nada irracional se revela a la razón humana en el orden/violencia o caos del mundo, sin referencia a Revelación ninguna. Dios existe como principio y sentido de lo que existe (Gran Diseño), pero no interviene en la historia y por ello la acción humana ha de orientarse a disminuir o eliminar el sufrimiento/dolor/injusticia (mal) y a potenciar la integración y la armonía mediante el conocimiento de nuestras condiciones de existencia. Si lo hacemos perseverantemente encontraremos recompensa en nuestra existencia misma o en alguna futura. Otra ventaja del deísmo es que facilita una asunción sociohistórica de Jesús de Nazaret sin remitirlo al Cristo-Jesús mítico. El deísmo contemporáneo surge del mismo ethos (seguridad, identidad) que generó la propuesta político-cultural de derechos humanos, es decir, en los procesos de gestación de las sociedades modernas y actuales. Entre sus principales méritos está el de no requerir materializarse en iglesias disgregadoras. Los deísmos claramente enfatizan su propuesta de consistir en una actitud experiencial hacia el mundo que desemboca en un estilo de existencia personal y social. Y sus propuestas, alejadas del prejuicio de tener la verdad en el bolsillo o en un libro, resultan enteramente compatibles con derechos humanos histórico-sociales y las luchas/esfuerzos progresivos e integradores (humanizadores) que ellos contienen. 
Retornando a las religiosidades más tradicionales, aunque minoritarias en América Latina, la mayor capacidad de quienes profesan alguna de las versiones del cristianismo protestante, que coinciden con la civilidad de lucha contenida por el reclamo y observancia de derechos humanos, está expresada en forma adecuada en la obra de Rubem Alves (1933-2014), originalmente presbiteriano, a quien puede considerarse con justicia generador de la corriente de pensamiento y acción conocida como Teología latinoamericana de la liberación. En su pensamiento, un Dios que no sufriese porque su pueblo, que deposita su fe religiosa en Él, no lucha históricamente por sus derechos a una vida justa y emancipada (Alves), no amerita considerarse, ni el pueblo ni Dios, cristiano. En relación con Alves, Larry Cox tendría razón. Con él, con Martin Luther King y con Hélder Cámara se encuentran personalidades cristianas que lucharon por derechos humanos. Pero ninguno de ellos redujo sus deseos y esperanzas a los límites que aquejan a Amnistía Internacional o Human Rights Watch. El desafío político y cultural contenido en una demanda por derechos humanos y por su ejercicio planetario excede con mucho los márgenes políticos, geopolíticos e ideológicos de esas organizaciones. La fe religiosa, diría Alves, está para más. Dios está para más. Él no se decanta nunca totalmente en institución alguna, sino en los sentimientos que las animan. La pregunta entonces sería: ¿qué sentimientos han nutrido hasta hoy el discurso y la práctica de derechos humanos? Ya sabemos que no se trata de sentimientos religiosos, aunque no resulten incompatibles con algunas maneras de experimentarlos. Tal vez se podría mejorar la pregunta: ¿qué tipo de sentimientos animan a la sociedad que inventa Derechos Humanos? ¿Y cómo se expresan en ellas tanto las religiosidades trascendentales como las fetichizaciones idolátricas? ¿Y los deísmos?

Según se avance en el estudio y debate de las respuestas se tendrá una más adecuada respuesta a la colaboración factible y constructiva entre religiosidades y derechos humanos en el mundo actual. Ni unas ni otros pueden presumir de no levantar justificadas sospechas.

\section{Referencias}

Alves, Rubem. Religión: ¿Opio o instrumento de liberación? Montevideo: Tierra Nueva, 1970. Impreso.

Bobbio, Norberto. El tiempo de los derechos. Madrid: Sistema, 1991. Impreso.

Catecismo de la Iglesia Católica. Impreso.

Cox, Larry. Los derechos humanos necesitan religión, en www.opendemocracy. net/openglobalrights/larry-cox/ los-derechos-humanos-necesitan-religi\%C3\%B3n. Digital.

Domínguez Cebrián, Belén. "Este 2016 bate el trágico récord de migrantes 
muertos en el Mediterráneo”, El País. España. En https://elpais. com/internacional/2016/10/26/ actualidad/1477493447_075762. html. Digital.

Fuentes Belgrave, Laura. La tibieza de quien peca y reza. Cambios en las creencias religiosas en Costa Rica. Heredia: SEBILA, 2015. Impreso.

Gallardo, Helio. Teoría crítica: matriz y posibilidad de derechos humanos. San Luis Potosí: Comisión Estatal de Derechos Humanos, Facultad de Derecho de la Universidad Autónoma de San Luis Potosí, 2008. Impreso

Hopgood, Stephen. Derechos humanos: ya pasó su vida útil, en www.opendemocracy.net/openglobalrights/ stephen-hopgood/derechos-humanos-ya pas\%C3\%B3-su-vida-\%C3\%BAtil. Digital.

King Jr., Martin Luther. Where Do We Go from Here: Chaos or Community? En es.wikipedia.org/wiki/ Martin_Luther_King. Digital.
Locke, John. Segundo tratado sobre el gobierno civil. San José, Costa Rica: EDUCA, 1997. Impreso.

Mora Mesén, Víctor Manuel. "La variopinta religiosidad contemporánea", La Nación (periódico), 29/10/2017, San José de Costa Rica. Impreso.

Pandeya, Ramchandra. "Fundamentos filosóficos de los derechos humanos. Perspectiva hindú", en Los fundamentos filosóficos de los derechos humanos. Barcelona: Serbal/UNESCO, 1985. Impreso.

www.segeplan.gob.gt/downloads/clearinghouse/politicas_publicas/ Grupos\%20Vulnerables/Pol\%C3\%ADtica\%20Ni\%C3\%B1ez\%20y\%20Adolescencia. pdf. Digital.

www.thegospelcoalition.org/coalicion/ article/martin-lutero-y-la-seguridad-de-la-salvacion. 